\title{
Strengthening Tolerance through Arts and Design Education
}

\author{
Dieter Mack* \\ Composition \\ University of Music Luebeck \\ Luebeck, Germany \\ *kamasan@t-online.de
}

\begin{abstract}
The current pandemic crisis has created a complete virtual reality that has even caused the existing virtuality of the so-called social media to be faced with a new challenge. Societies all over the world struggle with new social and cultural models as well as conflicts between what Andreas Reckwitz calls the fight between hyper-culture (individualism) and cultural essentialism (collectives). I will discuss that issue on an overall level including the aspect of tolerance, then turning to the idea of human coordinate systems and tolerance, and finally talk about some possible consequences to strengthen tolerance through music education. I argue that music practice when playing together and intercultural music education can contribute to strengthen tolerance.
\end{abstract}

Keywords—social media, new challenge, social and cultural models, tolerance

\section{INTRODUCTION}

Already in 2005, the German philosopher Harry Lehmann [1] published a remarkable article with the title "Globalisation and the Freedom of Arts". The author tries to define globalisation as an inevitable historical process and dwelled on the importance of the development of functional systems or communities without borders. In other words, globalisation has less to do with the change of territorial borders, but rather with the exponentially growing development of interest groups/communities. He called them the "...hidden agents..." globalisation. Hence, consequently, he comes to an interesting conclusion: "During the last time we could recognize a kind of flashback towards one's own local region. This is no antimovement to globalisation but its complementary side effect" [1]. Lehmann argues, a) positively that the new global societies penetrate each other, b) negatively, because regional/local resources could be exploited in a more efficient way by those global players, or as he called them, the "hidden agents" [1]. On the other hand, at the same time, that local flashback is a necessary supplementary counterforce in the sense of selfpreservation.

Recently, the sociologist Andreas Reckwitz [2] has put it in a more polarizing, though also threatening way, when he talks about the current cultural conflicts that are less than the fights between cultural realms à la Samuel Huntington. He reveals two rather opposing attitudes in dealing with culture itself. For him, there is a so called "hyper-culture" on one side, which fosters individualistic self-development and self-realisation based on a high degree of diversity regarding any global markets. On the other side he speaks of a "cultural essentialism" as a medium for a collective identity of communities. These communities are less related to locations but rather based on defined, limiting ideologies, whether philosophical, religious, or economic ones [2].

According to my opinion both opinions should be slightly extended. It seems to be completely utopian to believe that a human being of today is suited for a world society that increasingly permeates and interconnects with each other, although mostly on virtual platforms. Apparently, there is also a genuine interest if not urgent need for the local terrain. It has to do with personal identification or identity, which conveys stability and life security. Especially because of mostly alienated working situations, the search for orientation, fixed points of orientation and a kind of counselling in the sense of balancing seem to gain a new importance.

If one continues such thoughts, one may perhaps touch certain fundamental fears that humankind has tried to conquer since its beginnings. Therefore, it might be surprising that in an era of rationalisation and scientific explanations, speculative life ideologies or "religions" of any kind have a surprising success and intake. Some years ago, I received the news that some American states tried to implement a new legislation, that the term "evolution" should be banned from schoolbooks. This is less surprising, though absurd and frightening at the same time.

For many people, identity is not only assured by a strong self-consciousness, but also via a dialectic polarisation of the self towards one's own environment, unfortunately including various "enemy images". Only by the latter, many people are able to accept their own self, although for me, such a method is nothing more like a self-triggered pastoral fata morgana that automatically impedes or at least reduces tolerance. 
Once again, it does not need Samuel Huntington's [3] "clash of civilizations". The whole system of "human coordinate systems" or "systems of values" has become into disorder. Therefore, it seems to be less important when a wellknown global power wants to impose their fatal ideologies with messianic zeal and cunning mendacity. But it is equally less important if a bunch of wrong-led suicides still praise the accidental death of even own family members and declare them all as martyrs on the way to a heavenly paradise or whatever. Such perfidies are not measurable anymore. But in a frightening way they mark our everyday life, although there are much more important things to do and to take care of, because they have to do with the future of all humankind and not only a few.

In other words, Reckwitz' idea of cultural essentialism and this is the background of these two examples - seems typical for eras on a certain disorder but cannot really help to solve the problems.

COVID-19 at least could be regarded as a regulative to rethink about who we really are, how we need each other and how tolerance is perhaps the starting point for any kind of communication, the real as well as the virtual one; between communities of that essentialism or between individuals of Reckwitz' hyper-culture.

\section{DISCUSSION}

\section{A. About Human Coordinate System and Tolerance}

The arts as well - as an expression or even mirror of society processes - have to deal with such crude thoughts, although we would have to add individualism to globalisation and regionalism (the local). However, exactly here it becomes difficult, because the existing "points of orientation" as a parametrical destination seem to vanish increasingly. Lehmann calls these points of orientation "archimedic points" in a kind of analogy to that famous saying of Archimedes. They are essential for life orientation of most humans; and the lack of them - now getting back to arts - represents a significant feature of postmodernism. By that - and with the words of Lehmann - the central feature of arts, the subjectobject relation vanishes. Consequently, it would be the end of the artist and the artwork as well. But at the same time, we would face the highest degree of mutual tolerance. Art education could be reduced to any kind of creative activity, and the doing, the action itself is more important than the result. Or the other way around: Through this kind of anarchic and open sound production (I can hardly call it art then), we could experience tolerance as a kind of "anything goes", as long as the own activity does not interfere with those from others. A paradise-like situation?

I would like to propose another model like the one from Lehmann, or at least I would like to extend it again. In fact, later in his article, Lehmann dismisses postmodern "anything goes" completely. For him, an artistic decision is always depending dialectically on those points of reference, and therefore corelates with the common notion of the need of such systems for the respective societies or communities as well. One may even ask whether in art music has ever existed a kind of postmodern attitude without coordinate systems? Serious artists will always newly create their coordinate systems. The negative notion in postmodernism should then be based on another argument, which is the lack of critical self-reflexion on the search of one's own coordinate systems. However, if we talk about those coordinate systems as something transindividual, then its lack might really been something essential. Nevertheless, there are other positions like that one from Jonathan D. Kramer [4] who insists that there are certainly coordinate systems in postmodernism. According to Kramer, all coordinate systems are systematically questioned, but never denied. Therefore, postmodernism has never been a stylistic epoch but rather an attitude. And here I would completely agree, because this is a basic pre-requisite in arts and a strong argument as well, why a broad palette of art education may support the notion of tolerance in an educational situation. However, we all know how extremely far, especially today's music education is away from those goals.

When will educators learn that knowledge of facts has nothing to do with art education? It even impedes the development of tolerance. That tiny glimpse of knowledge that can be taught in a school situation is so limited. If a pupil automatically takes it as "pars pro toto", we have just started to implant the seed of intolerance.

As a first summary, we can say that we face a dilemma if we try to bring art and society together. If we regard the human desire for those "archimedic points of orientation" (Lehmann), whether in art, everyday life or whatever, then it is quite counter-productive in today's global world. The degree of acceptance of the Other or the alien will disappear in favour of the own self-preservation. The ideal of an open or flexible coordinate system or the non-existence of it at all will remain utopian. Here, I still miss a comprehensive answer from Andreas Reckwitz because coordinate systems or archimedic points are typical for communities of cultural essentialism, but it also happens with individuals of the hyper-culture.

I think the last months have given us some good examples during the Corona crisis. The more we became aware that we really do not know what the cause is or what the remedy is, what the best behaviour would be etc., the more spiritual theories of any kind became popular. New communities in the sense of Reckwitz' "cultural essentialism" with strict archimedic points develop. And as real human communication has been interrupted temporarily, social platforms have replaced it. The virtual became reality!

People are frightened that they do not receive precise arguments, even if they would be wrong. But they need their "remedy", their coordinate system of understanding. The simple answer that there is something that we really cannot explain for a while, makes people anxious. Even religion or its representatives can hardly give satisfying the answers, except some extremists who certainly accuse any 
other party of being responsible for it. The peak of religiously motivated irrationalism was the following - and this was pure reality in last March: A vice-minister of a SEA country announced in public: COVID 19 is only a disease for people with the wrong belief; and if you have the right one, nothing will happen to you!

Here I would like to get back to my own approach in that big ocean of opinions and ideologies. I am convinced that the ability to make artistic decisions must not necessarily be related (or being based) on points of reference, without falling into the trap of a postmodern aesthetic of indifference. By that, I strongly support the idea of Reckwitz' hyper-culture, and its implicit plural and tolerant individualism.

One to refer to a so-called "Koan" in Japanese ZenBuddhism. A "Koan" is a special problem which - because of its implicit contradiction - cannot be grasped rationally. Only an encompassing occupation with it may ultimately lead to a kind of transcending which goes beyond the contradiction. But it can only be experienced individually. It can be easily compared with artistic decision processes, far away from traditional dialectic processes and certainly also far away from postmodern dissolution tendencies of any kind.

A statement by French symbolist Stephane Mallarmé [5] has always been my guideline in this regard:

I have created my work only by elimination. And each truth, that I have gained has been coming out of the loss of an impression, that has destroyed itself in the very moment of its appearance and which - because of the freed darknessallowed me to get deeper into the feeling of the absolute darkness [5].

The quote - that can hardly be accused of being written with a post-modernist attitude - also fosters the lack of "archimedic points" without losing orientation or falling into the trap of "total subjectivity" as Lehmann would name it. Especially that last term by Lehmann seems to be questionable. For Lehmann it implies the complete lack of criteria, and therefore the lack of freedom for a decision in the cauldron of arbitrariness.

However, I think that term "total subjectivity" can be seen the other way around as well. It is the radical demand for selfresponsibility which develops only out of the "thing" itself. Like with Mallarmé, who had to give up himself, raising up to experience a new kind of "objectivity of radical subjectivity" during an artistic process. Such a process cannot be foreseen. One has always to jump into the "black hole" or the "cold water", knowing that it is only oneself, who experiences it and who has to carry all related consequences. Let me finish this more abstract section on artistic responsibility with a second summary.

We have seen that individual freedom on the one side (hyper-culture) and total integration into a coordinate system of a community (cultural essentialism) are both extremes that tend to impede openness or tolerance. It is clear and essential for the second type. Complete individual freedom potentially also lacks self-responsibility. But individual freedom can only go so far as the freedom of others is not touched or limited. Here, tolerance is the crucial term. We can cultivate such kind of tolerance in learning to make artistic decisions with a full selfresponsibility: Strawinsky once claimed that artistically he has the utmost freedom after a clear limitation at first. Then the creative challenge comes into being and leads us through a complex process, always critically weighing things with others. It is an exhausting process and a never ending one. So Reckwitz' notion of hyper-culture is correct to describe a tendency of our time; but that complete availability and seemingly individualism asks for certain consequences.

The total integration into coordinate systems, the cultural essentialism, as a response to the fear of the cauldron of this world is understandable; but self-responsibility is often put aside, in favour of mostly obscure ideologies. People give their lives and souls and thoughts mostly into the hands of populists, ideologists and charlatans. The danger is implicit in any of the world's religions. We know that religion itself is primarily a tool to seemingly "understand" the non-understandable. In its best, it accepts plurality. Many years ago, a Balinese priest asked how me - a Western Christian, because he could not think otherwise - could pray in their temple during a ceremony? Before I answered, he gave the answer himself saying: This was a stupid question. If there is something beyond us, it is the same for all. We just name it differently. I think this was a wise comment which I would love to hear more from clerics of any other religion.

\section{B. When Does Music Matter and How?}

In this section, I would like to formulate some statementlike points on the functions and contexts of music regarding tolerance. Undeniably, music matters! How far is this due to cultural immanent criteria, and how far is it more transcultural or global? I might not be able to give a comprehensive answer to that, but it is a first attempt in the realm of an almost limitless topic.

Let me make some pre-liminary statements and partly answer the implicit questions:

- Music is an integral part of any ethnic group in the world: for religious purposes in the widest sense of its meaning as well as for social purposes of identity and even for social welfare. To my knowledge, there is no ethnic group that completely denies any kind of organized sound in its culture. Which sound can trigger special behaviors as for example trance etc., is culturally immanent and cannot be detected in the music matter itself. Accepting this diversity is already an important step to tolerance.

- It is opposite with national anthems: Every nation has its national anthem as a symbol of identity. However, most national anthems sound quite the same. They use almost the same music matter, a few exceptions included. Only the respective language of the text and some potential local references are different. Is it the 
music matter here, or the historically grown determination and the ceremonial sermon around it? Perhaps bit is both, because an anthem shall trigger collective behavior or consciousness, but it is not a sign of tolerance.

- Music has become a part of our everyday environment, especially in an urban context. Is there still a quiet place? Where can we still digest the sounds of silence? Music sounds in shopping malls - not only one music for the whole building; every shop seems to have its own PA with music that should stimulate the respective group of preferred buyers. Music sounds in a restaurant or a bar. If we speak about pollution of our environment as one of our main global concerns, we also should with a few exceptions - start to talk about pollution through music matter that tends to lose its original semantic destination. Here the term tolerance seems to receive a different meaning. Should we really tolerate that kind of sound pollution of our environment? Perhaps we have to, but it must be clear that especially such functional music tend to impede tolerance because of the implicit conditioning process.

- Related to point 3, we face a completely new situation of conditioning through sound. Sometimes one feels like a "white mouse in a glass box of a laboratory", and virtual scientists are waiting how I react to various stimuli. You certainly have heard the term "muzac", which is functionally produced music that should influence your shopping behavior. Apparently, musical matter also "matters" - at least seen from an economic standpoint and less regarding tolerance.

- Earplugs: Beside the potential danger that one can hardly recognize real sounds in one's changing environment, we do not know enough about the physical damage by continuous exposure. I do not want to be too negative, but the ongoing exposure of the cochlea and its cells on the Basilar membrane can cause serious damage, but damage that develops almost unnoticed until it is too late. Don't forget: most music that people "hear" - they don't listen to! - is on a single dynamic level and mostly focuses on a steady beat. My question is: To which degree our acoustic sensibility and differentiation will increasingly vanish, because of such a continuous exposure? Are we still able to listen to the variations of the wind in the mountains or to a piece like Morton Feldman's "King of Denmark"? Are we still able to be tolerant to diversity?

- On the other hand, the healing effect of music has become an increasing field of interest in science - not to speak about thousands of esoteric music therapies, which I cannot mention here.

- And then, there is the educational effect of music making. Arts are increasingly disappearing from public school's curricula. Especially music - if it is taught at all - has become either a torture, because of stupid memorizing theory, or it is a healthy relaxing break to compensate the mental burdens of other subjects like language and natural sciences. I know, this happened also 40 or 50 years ago, or even earlier. But today, it seems much more evident, at least in my country. It is nothing new to state that music may have a relaxing element. And I would agree, why not? If at the same time creativity and social sensibility are growing, I strongly support that kind of relaxing function. To create sound occupies parts of the brain that would degenerate if these parts are not continuously trained. And as a side effect, social competence - tolerance! may grow. But therefore, it needs a high degree of diversity of music matter.

I remember a good statement (that I have already quoted various times) by the author Jurek Becker already in 1995 in the German magazine "DER SPIEGEL" (2/1995, page 160) that indirectly refers exactly to the problem of tolerance, responsibility and diversity:

To listen to pop music the whole day, as many people do, or to operetta, as one of my female neighbors does, is something like to avoid intentionally fantasy. However, fantasy is probably an important pre-requisite to get along with one's life in a balanced way. Therefore, the continuous output of music seems to be as well something irresponsible: As if we want to calm down the listeners like inhabitants of a hospital for mentally sick people. As if it would be something desirable to keep them in a state of non-thinking, in an atmosphere of dumbness (...) It is not so much the problem that the people lack helping tools for orientation. It is much more serious that our own ability to find our own orientation becomes stunted.

Music matters a lot, and the different situations tell us how musical material may influence human beings, including tolerance.

\section{Strengthening Tolerance through Music Education}

This brings us to the last point. What can art education achieve to support or strengthen that urgently needed tolerance? To give a comprehensive answer here on the background mentioned above, I see mainly two points regarding the field of music:

- Strengthening tolerance through music practice when playing together

- Strengthening tolerance through intercultural music education

Before I will comment on both topics, I have to admit that from my point of view, all efforts regarding strengthening tolerance via the medium music will completely fail, if some essential pre-requisites are not fulfilled. Many people still believe that the main body of music education in public schools is a) learning historical data about composers and their works; 
b) learning about notation of music and c) singing some songs - in many countries politically motivated.

Despite the disappointing fact that these three "viruses of music education" are still quite common practice, I hope that we all agree that music education has to be based on completely different fundaments. I could at least agree with the third point, because it includes a practical activity. But as already mentioned, the background is mostly not a musical but a political one. We all know it quite well here in Indonesia with the so-called "lagu wajib". As I have written various articles on that topic since 1992, I do not want to repeat something here. But how could we describe then what music education is? It is in the first place the effort to develop the listening abilities of a pupil. Developing means to enable a person to listen more differentiated to any kind of music and giving him or her some tools to learn or better to understand music languages. The famous saying in music psychology is still: "You only hear what you know". It means that in a new piece of music, our mind always selects or prioritizes those elements that sound familiar. We also hear everything else, but we mostly do not recognize or understand it; or we put it on a secondary if not ternary level of perception. Such learning processes for our brain do not take place via the above-mentioned data, but rather by the own musical practice and listening experience. Edwin E. Gordon's term "audiation" is still in high demand, although his concept has already been extended and partly relativized. But the basic assumption is still valid.

1) Strengthening tolerance through music practice when playing together: Getting back to my main two points, I would like to start with most simple one. Musical practice with more than one person, is already the starting point for strengthening tolerance. It even does not need any knowledge of an instrument nor of notation. It can be practised on an improvisational level. Good improvisation, even as a Duo, asks for taking care of the intentions of one's partner. It means that in a learning process we can start with simple exercises just using the human voice: Player A suggests something, and player B starts to react to it. Reacting can happen in various ways from joining in until rejecting completely. Between both extremes, there are lots of steps and variations. If the pupils still have difficulties to create organised sound as the very first step, a teacher may suggest some motives, phrases or sounds. In most cases a kind of dialogue will appear. It also may happen that one person wants to be prominent and the other just accompanies. A teacher should prepare an encompassing repertoire of possibilities and situations. Nothing must be longer than a minute. After each attempt, an evaluation must take place with the players, as well as the whole class who was listening.

My experience is that the very beginning is always the hardest, and the teacher must be prepared for that. Sooner or later the pupils will get into it. It is also important that the starting musical elements do not refer to a certain defined musical language. So-called "rules" may develop automatically during the musical practice. Step by step, this process may include bigger groups but not more than five or six persons. In a further step, the same "games" may be done with simple percussion instruments or whatever is available. It is always essential that the role-playing in a group is intensively discussed. By that, tolerating something that is done by someone else and reacting to it reveals a new consciousness about otherness, responsibility, and mutual acceptance.

2) Strengthening tolerance through intercultural music education: While the first category is also helpful to learn about sound and other musical parameters, including their meaning and function in a context, the second category has more to do with the consciousness of different cultural identities. It already takes place on that individual level, if with would apply the term culture to individual behaviour as well (see the term "hyper culture" in the first part of my talk). The question where the "intercultural" starts is not easy. In a country like Indonesia, the whole nation is signified by a high degree of interculturality. Take a Balinese, a Sundanese and a Batak - just to name three cultural realms - and the differences are more significant that between a German, a French and a British.

Especially for Indonesians it is a basic characteristic of the nation to achieve unity in diversity. This process is an ongoing one that will never end. Here I would like again to recall the beginning of my presentation when I spoke about the mutual dependency of the Global and the Local. And we also know how difficult it is to be tolerant regarding social behaviour, religion, social status etc.

Musical experience may be a helping tool to ease ethnic tensions of any kind, accept the Otherness but also learn from the latter. This assumption is based on the strong belief that music is always a medium that transports cultural identity and cultural memory on various levels. I must admit that looking back on my now 66 years I am grateful that I had the opportunity to experience diversity in an encompassing way. It has enriched my life, giving me new stimulations and has helped me to see my own culture from outside. I think this was and still is a very "healthy" experience, though not always a pleasing one.

\section{CONCLUSION}

I conclude my discussion that the fight between hyperculture (individualism) and cultural essentialism (collectives) still exists. I propose a strategy for strengthening tolerance through music education, such as music practice when playing together and intercultural music education in order to know the other better. The acceptance of diversity and otherness is the fundament of human tolerance.

\section{REFERENCES}

[1] H. Lehmann, "Globalisierung und die Freiheit der Künste," Musik \& Ästhetik, vol. 9, no. 33, pp. 86-103, 2005. 
[2] A. Reckwitz, Das Ende der Illusionen: Politik, Ökonomie und Kultur in der Spätmoderne. Frankfurt: Suhrkamp, 2019.

[3] S.P. Huntington, The clash of civilizations? In Culture and politics (pp. 99-118). New York: Palgrave Macmillan, 2000.
[4] J.D. Kramer, "The nature and origins of musical postmodernism," Postmodern music/postmodern thought, pp. 13-26, 2002.

[5] M. Blanchot, Der Gesang der Sirenen. Essays zur modernen Literatur. Frankfurt, 1982 